\title{
Post Hoc Analysis of Nutritional Status in Patients with Transthyretin Familial Amyloid Polyneuropathy: Impact of Tafamidis
}

Ole B. Suhr • Isabel M. Conceição • Onur N. Karayal • Francine S. Mandel •

Pedro E. Huertas • Bo-Göran Ericzon

To view enhanced content go to www.neurologytherapy-open.com

Received: October 8, 2014 / Published online: December 11, 2014

(c) The Author(s) 2014. This article is published with open access at Springerlink.com

\section{ABSTRACT}

Introduction: Gastrointestinal symptoms are common among patients with transthyretin familial amyloid polyneuropathy (TTR-FAP). This post hoc analysis evaluated the

Trial registration: These data were derived from two trials registered at clinicaltrials.gov as NCT00409175 and NCT00791492.

Electronic supplementary material The online version of this article (doi:10.1007/s40120-014-0023-8) contains supplementary material, which is available to authorized users.

O. B. Suhr $(\bowtie)$

Department of Public Health and Clinical Medicine, Umeå University, 90185 Umeå, Sweden

e-mail: ole.suhr@medicin.umu.se

I. M. Conceição

Department of Neurosciences, Centro Hospitalar Lisboa Norte-Hospital de Santa Maria, Lisbon, Portugal

I. M. Conceição

Translational and Clinical Physiology Unit, Faculty of Medicine, Instituto de Medicina Molecular, Lisbon, Portugal

O. N. Karayal · F. S. Mandel · P. E. Huertas Pfizer Inc., New York, NY, USA

Bo-GöranEriczon

Karolinska Institutet, Stockholm, Sweden nutritional status of TTR-FAP patients treated with tafamidis while enrolled in clinical trials. Methods: Nutritional status was measured by the modified body mass index $(\mathrm{mBMI}=\mathrm{BMI} \times$ albumin $\quad$ level $) . \quad$ Treatmentrelated changes in $\mathrm{mBMI}$ were reported for 71 Val30Met TTR-FAP patients who completed an 18-month, randomized, double-blind, placebocontrolled trial and who continued into its open-label, 12-month extension.

Results: At month 18, mBMI worsened in the placebo group $(n=33) \quad\left(-33 \pm 16 \mathrm{~kg} / \mathrm{m}^{2} \mathrm{~g} / \mathrm{l}\right.$, $P=0.04$ versus baseline) but improved in the tafamidis group $(n=38)\left(+37 \pm 14 \mathrm{~kg} / \mathrm{m}^{2} \mathrm{~g} / \mathrm{l}\right.$, $P=0.01$ versus baseline) such that the effect size between the groups was statistically significant $\quad(P=0.001)$. By month 30 (completion of the open-label extension), placebo patients with 12 months of tafamidis treatment and tafamidis-treated patients with 30 months of treatment both tended to increase their mBMI $\left(28 \pm 19 \mathrm{~kg} / \mathrm{m}^{2} \mathrm{~g} / \mathrm{l}\right.$ and $16 \pm 18 \mathrm{~kg} /$ $\mathrm{m}^{2} \mathrm{~g} / \mathrm{l}$, respectively). Increase in BMI was most pronounced in patients with low BMI at entry into the studies.

Conclusions: $\mathrm{mBMI}$ is well suited to monitor disease progression in TTR-FAP patients. The 
delay in neurological deterioration brought about by tafamidis treatment in clinical trials is associated with improvements in, or maintenance of, mBMI.

Funding: This study was sponsored by Pfizer Inc., New York, USA.

Keywords: Disease modification; Modified body mass index; Neurology; Tafamidis; Therapeutic use; Transthyretin amyloidosis; Transthyretin familial amyloid polyneuropathy

\section{INTRODUCTION}

Transthyretin familial amyloid polyneuropathy (TTR-FAP) is the most common phenotypic presentation of the TTR amyloidoses, a group of fatal autosomal dominant disorders of variable penetrance caused by mutated TTR that facilitates dissociation of TTR tetramers into amyloidogenic misfolded TTR and subsequent assembly into TTR amyloid which deposits into various organs [1]. The particularly affected anatomical structures are the peripheral and autonomic nerves, heart, gastrointestinal tract, kidneys, eyes, and connective tissue of the carpal ligament $[1,2]$. Worldwide, $>100$ point mutations of the TTR gene located on chromosome 18q12.1 have been described, nearly all of which can lead to amyloidosis [3]. The vast majority of TTR-FAP cases (85\%) are associated with replacement of valine by methionine at position 30 of the protein (Val30Met) [1, 3, 4].

The hallmark of TTR-FAP is neurodegeneration of sensory, motor, and autonomic nerve fibers [1]. Gastrointestinal features are prominent in most cases, vary considerably in type and severity both within and between TTR mutations, and may present before the onset of peripheral polyneuropathy
[5]. Weight loss, nausea, and alternating bouts of constipation and diarrhea are common during early-stage disease, while malabsorption, severe chronic diarrhea, and cachexia often occur during late-stage disease [5-10]. Severe malnutrition and opportunistic infections lead to death in these late-stage patients [10, 11].

Body mass index (BMI) is a suboptimal measure to assess the clinical status of patients affected by the wasting characteristic of TTRFAP since high BMI values can be observed in edematous malnourished patients due to low serum albumin. Modified BMI (mBMI) (the product of BMI and serum albumin) corrects for the effect of hypoalbuminemia and is a better reflection of overall nutritional health. In clinical practice, mBMI is an effective tool for monitoring TTR-FAP progression as it is closely related to time before death, duration of gastrointestinal disturbances, malabsorption, functional capacity, and survival after liver transplant $[11,12]$. Furthermore, mBMI reports on hepatic synthetic capacity, and on neurogenic and absorptive gastrointestinal functions. As such, mBMI should be considered an integrative physiologic indicator for patients with TTR-FAP.

Tafamidis is a once-daily, orally bioavailable, pharmacological chaperone and kinetic stabilizer of TTR approved for the treatment of adult patients with TTR-FAP in several countries $[13,14]$. Tafamidis binds with high affinity and selectivity to patient-derived wild-type TTR and to most amyloidogenic TTR variants capable of forming tetramers, including the Val30Met TTR variant [13]. In a randomized, placebocontrolled trial (Fx-005, NCT00409175) of patients with Val30Met TTR-FAP [15], tafamidis was well tolerated and associated with slowing the progression of peripheral neurologic impairment and was better at 
preserving quality of life versus placebo [15]. One of the other multiple outcome measures used to evaluate the efficacy of tafamidis was nutritional status at 18 months, which improved in the tafamidis group but worsened in the placebo group [15]. Furthermore, the deterioration in mBMI observed among placebo-treated patients in this study was reversed by tafamidis during this study's 12-month open-label extension phase [16].

Given the prominent role that nutrition plays in TTR-FAP progression, the objective of the present post hoc analysis was to present a more detailed account of the effects of tafamidis on nutritional status as measured by $\mathrm{mBMI}$ and its components in patients with TTR-FAP who participated in these clinical trials.

\section{METHODS}

\section{Patients and Study Designs}

The full methodologies of the two international multicenter trials (ClinicalTrials.gov: Fx-005, NCT00409175; Fx-006, NCT00791492) have been published previously $[15,16]$. Eligible patients in the Phase IIb, randomized, controlled trial were consenting men and women aged 18-75 years with a documented Val30Met TTR mutation and symptomatic, biopsy-confirmed TTR amyloidosis. Patients were randomly assigned in a 1:1 ratio to either oral tafamidis $20 \mathrm{mg}$ or placebo once daily for 18 months, and completers were subsequently eligible to enroll in the single-arm extension study and receive the same tafamidis dosage regimen for 12 months [16]. Thus, there were two treatment sequence groups in the extension study: patients randomized to 18 months of tafamidis who continued to receive tafamidis (tafamidis-tafamidis) and patients randomized to 18 months of placebo who were switched to tafamidis (placebo-tafamidis). Although patients and investigators were aware that all patients were receiving tafamidis during the extension study they remained blinded to the treatment assignment in the randomized phase.

\section{Compliance with Ethics}

Both study protocols were approved by the local scientific ethical committees and regulatory authorities, and conducted in accordance with the ethical standards of the responsible committee on human experimentation (institutional and national) and with the Helsinki Declaration of 1975 , as revised in 2000 and 2008 [17]. Informed consent was obtained from all patients for being included in the study.

\section{Clinical Assessment}

In both studies, mBMI was calculated as the product of the BMI and serum albumin concentration. Height, weight, and albumin were measured during the baseline visit, and weight and serum albumin were measured during each follow-up visit (every 6 months during treatment) up to and including the month 30 end-of-treatment visit.

\section{Analysis Populations}

A longitudinal mBMI analysis was conducted on the intent-to-treat (ITT) population of the extension study, defined as those patients who completed the randomized, controlled study per-protocol, enrolled in the extension phase, and received at least one dose of study medication without an interruption of $>2$ months between the two studies. 


\section{Statistical Analysis}

All efficacy data analyses were performed using descriptive statistics (mean \pm standard deviation for baseline parameters and least squares mean \pm standard error for ontreatment comparisons) using $\mathrm{SAS}^{\circledR}$ version 9.1.3 $\quad$ SAS $^{\circledR}$ Institute Inc., Cary, North Carolina, USA). For each efficacy measure, change from baseline to each treatment time point was analyzed using a repeated measures mixed model analysis of variance for betweengroup comparisons. The model used an unstructured covariance matrix; with treatment group and treatment group-bymonth interaction as fixed effects, and subject as a random effect. Within-group comparisons were performed using paired $t$ tests.

To examine possible differential effects of baseline BMI on change from baseline, categorical analyses stratified by baseline BMI strata [BMI $<20 \mathrm{~kg} / \mathrm{m}^{2}$ (underweight), BMI $20-25 \mathrm{~kg} / \mathrm{m}^{2} \quad$ (normal), BMI $>25 \mathrm{~kg} / \mathrm{m}^{2}$ (overweight)] were performed. Treatment group comparisons and differences between BMI strata at each visit were analyzed using repeated measures mixed models with change from baseline as the dependent variable, and treatment, baseline BMI strata, and treatmentby-BMI strata as fixed effects.

\section{RESULTS}

\section{Patient Disposition}

The flow of patients through the randomized, controlled study and its extension phase has been described previously and is summarized in Fig. $1[15,16]$. The salient observation was the large proportion of patients who discontinued randomized treatment due to availability of a donor liver rather than due to any study-related cause. As a result, of the 125 patients (64 treated with tafamidis and 61 treated with placebo) who constituted the ITT population of the randomized, controlled study, only 47 and 44 patients in the tafamidis and placebo group, respectively, completed the trial. Of these 91 patients, 86 patients (94\%) agreed to enroll in the extension study and all but one patient received at least one dose of tafamidis. Fourteen patients had treatment with tafamidis interrupted for at least 2 months between studies and were excluded from the analysis population, as was one patient who discontinued due to availability of a donor liver, leaving 71 patients in the ITT population of the extension study (38 treated with tafamidis and 33 treated with placebo). This treatment interruption was due to a delay in regulatory approval at two South American sites and one site in Portugal.

\section{Baseline Demographics and Clinical Characteristics}

The medical histories of the extension study's ITT population at the baseline of the randomized, controlled trial were representative of an early-stage TTR-FAP population: nearly all patients (>90\%) reported nervous system disorders, most reported gastrointestinal symptoms (>70\%), mean values for serum albumin, BMI, and mBMI were normal; nutritional status was well-preserved; and there was modest impairment of Neuropathy Impairment ScoreLower Limbs (NIS-LL) and Norfolk Quality of Life-Diabetic Neuropathy total quality of life score (Table 1) [18-21]. There were no obvious differences in demographics or clinical characteristics, including nutritional health, between the tafamidis and placebo groups at 


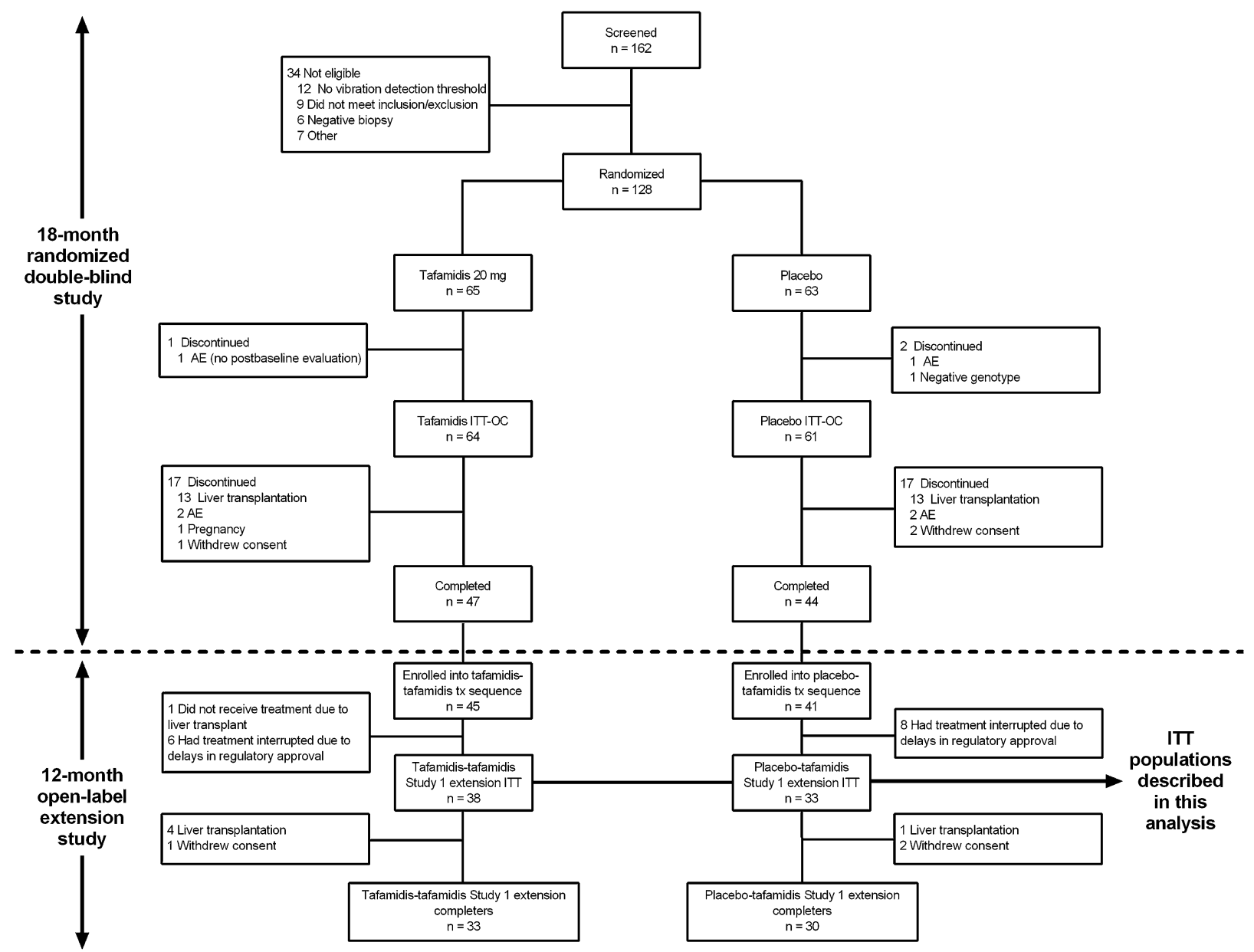

Fig. 1 Patient disposition in the randomized, controlled trial and its 12-month open-label extension. $A E$ adverse event, ITT intention to treat, ITT-OC ITT-observed cases

baseline. At least half of the subjects had disease onset prior to their fifth decade (i.e., early-onset Val30Met TTR-FAP). Recipients of placebo exhibited worse neurological impairment and nutritional health at the start of the open-label extension compared with patients who had been treated with tafamidis. Six of 85 patients (7\%) had a medical history of peripheral edema.

\section{mBMI}

Figure $2 \mathrm{a}$ shows that, over the 18-month, randomized, treatment period, placebo recipients experienced a worsening in $\mathrm{mBMI}$ at each on-treatment study visit from
$1,020 \pm 244 \mathrm{~kg} / \mathrm{m}^{2} \mathrm{~g} / \mathrm{l}$ yielding a change from baseline to month 18 of $-33 \pm 16(P=0.04)$. In contrast, over the same time period, patients treated with tafamidis experienced an improvement in mBMI at each on-treatment study visit (from $1,032 \pm 167 \mathrm{~kg} / \mathrm{m}^{2} \mathrm{~g} / \mathrm{l}$ to give a change from baseline to month 18 of $+37 \pm 14$, $P=0.01)$. This represents an adjusted least squares mean difference of $73 \pm 21 \mathrm{~kg} / \mathrm{m}^{2} \mathrm{~g} / \mathrm{l}$ between the tafamidis and placebo groups $(P=0.001)$.

This between-group difference widened slightly when patients entered the extension phase but statistical significance was lost because the sample size had decreased relative 
Table 1 Demographics and clinical characteristics of the extension study's ITT population, recorded at baseline of the randomized, controlled trial

\begin{tabular}{lcc}
\hline Parameter & $\begin{array}{c}\text { Tafamidis-tafamidis } \\
(\boldsymbol{n}=\mathbf{3 8})\end{array}$ & $\begin{array}{c}\text { Placebo-tafamidis } \\
(\boldsymbol{n}=\mathbf{3 3})\end{array}$ \\
\hline Median age, years (range) & $36.5(25$ to 74$)$ & $34.0(23$ to 71$)$ \\
Female, $n$ (\%) & $21(55)$ & $18(54)$ \\
Caucasian, $n$ (\%) & $37(97)$ & $33(100)$ \\
Median duration of TTR-FAP symptoms, months (range) & $17.5(3$ to 268) & $18.0(2$ to 133) \\
Mean height, m (SD) & $1.66(0.1)$ & $1.67(0.1)$ \\
Mean weight, kg (SD) & $65.1(12.4)$ & $64.4(14.4)$ \\
& $66.2(11.9)^{\mathrm{a}}$ & $63.3(14.1)^{\mathrm{a}}$ \\
Mean serum albumin, g/l (SD) & $43.9(3.5)$ & $44.2(4.2)$ \\
Mean BMI, kg/m ${ }^{2}$ (SD) & $44.7(3.4)^{\mathrm{a}}$ & $43.1(4.0)^{\mathrm{a}}$ \\
& $23.6(3.6)$ & $23.1(5.2)$ \\
Mean mBMI, kg/m ${ }^{2}$ g/l (SD) & $23.9(3.0)^{\mathrm{a}}$ & $22.7(5.2)^{\mathrm{a}}$ \\
& $1,031.6(166.5)$ & $1,020.2(244.3)$ \\
NIS-LL (range 0-88) & $1,068.4(142.4)^{\mathrm{a}}$ & $990.1(265.0)^{\mathrm{a}}$ \\
Mean (SD) & & $11.6(14.5)$ \\
Median (range) & $6.8(10.0)$ & $6.0(2$ to 57) \\
TQOL, median (range) & $4.0(0$ to 49$)$ & $28(-1 \text { to } 96)^{\mathrm{a}}$ \\
\hline
\end{tabular}

BMI body mass index, ITT intent-to-treat, NIS-LL Neuropathy Impairment Score-Lower Limbs, $S D$ standard deviation, TQOL Norfolk Quality of Life-Diabetic Neuropathy total quality of life, TTR-FAP transthyretin familial amyloid polyneuropathy

a At baseline of the open-label extension study

to month 18 of the randomized controlled trial: patients who were originally randomized to placebo had a mean baseline mBMI value of $990 \pm 265 \mathrm{~kg} / \mathrm{m}^{2} \mathrm{~g} / \mathrm{l} \quad$ compared with $1,068 \pm 142 \mathrm{~kg} / \mathrm{m}^{2} \mathrm{~g} / \mathrm{l}$ in patients originally randomized to tafamidis $(P=0.08)$. Once placebo patients commenced treatment with tafamidis, the worsening in mean mBMI observed during the 18-month placebo phase was reversed during the open-label, 12-month, extension phase (Fig. 2a). At the conclusion of the open-label extension study, the patients in the placebo treatment group had a change from baseline increase in mBMI of $28 \pm 19 \mathrm{~kg} / \mathrm{m}^{2} \mathrm{~g} / \mathrm{l}$ while the tafamidis patients had an mBMI increase of $16 \pm 18 \mathrm{~kg} / \mathrm{m}^{2} \mathrm{~g} / \mathrm{l}$, there being no statistically significant difference between the two groups $(P=0.64)$. mBMI changes from baseline to month 18 were highly comparable across the study centers, with the tafamidis groups having a mean gain in mBMI at every study center, whereas the placebo groups had a 


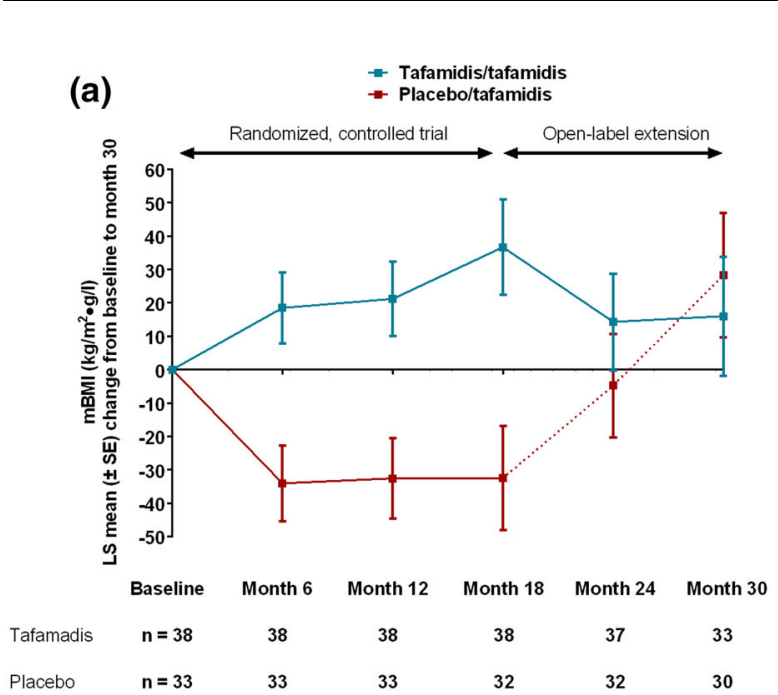

(b) $\quad$ - Tafamidisittafamidis

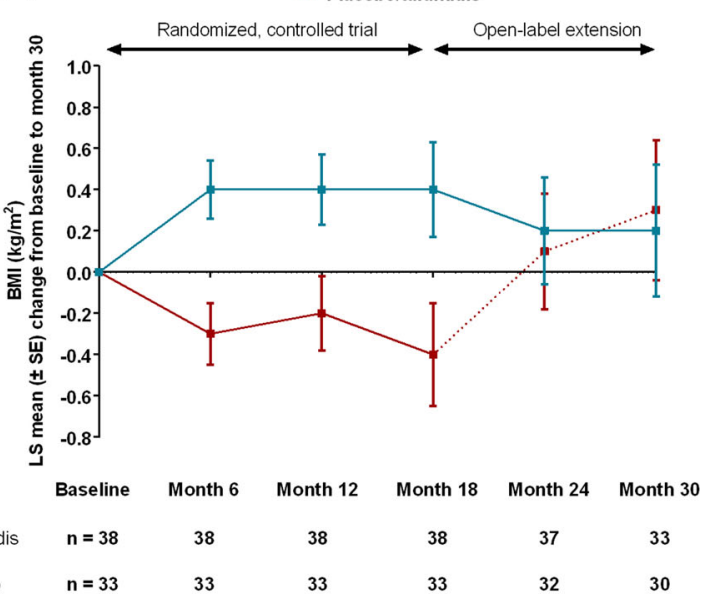

(c)
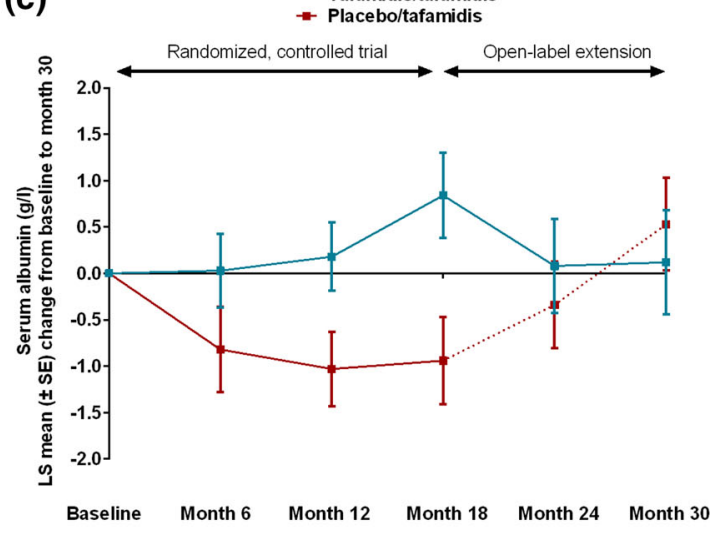

$\begin{array}{lllllll}\text { Tafamadis } & \mathrm{n}=38 & 38 & 38 & 38 & 37 & 33 \\ \text { Placebo } & \mathrm{n}=33 & 33 & 33 & 32 & 32 & 30\end{array}$

4 Fig. 2 Changes in mBMI (a), BMI (b), and albumin (c) in the randomized, controlled trial and its open-label extension. $B M I$ body mass index, $L S$ least squares, $m B M I$ modified BMI, SE standard error, TTR-FAP transthyretin familial amyloid polyneuropathy

mean mBMI loss at every study center (Pfizer Inc., data on file).

The reversal of mean mBMI decrements observed after patients switched from placebo to tafamidis in the extension study manifested because of improvements in both components of the mBMI (BMI and serum albumin level) during the tafamidis treatment phase (Fig. 2b, c).

To examine the effect of initial BMI on changes from baseline in BMI, the patients were divided into three groups based on baseline BMI: underweight (BMI $<20 \mathrm{~kg} / \mathrm{m}^{2}$ ), normal (BMI between $20 \mathrm{~kg} / \mathrm{m}^{2}$ and $25 \mathrm{~kg} / \mathrm{m}^{2}$ ), or overweight (BMI $>25 \mathrm{~kg} / \mathrm{m}^{2}$ ). Tafamidis patients who were underweight initially gained in BMI during the study period to month $18 \quad\left(1.5 \pm 0.6 \mathrm{~kg} / \mathrm{m}^{2}\right)$ (Fig. 3). Smaller gains were observed in the normal BMI group $\left(0.5 \pm 0.3 \mathrm{~kg} / \mathrm{m}^{2}\right)$, whereas a decrease in BMI was observed in patients in the overweight BMI group $\left(-0.5 \pm 0.4 \mathrm{~kg} / \mathrm{m}^{2}\right)$. For patients in the placebo group, the BMI was relatively constant during the observation period, again with a tendency for increased loss in the overweight group at month 18 . In the tafamidis-tafamidis treatment sequence group at month 30, patients who were underweight or normal at baseline showed moderate increases in BMI (underweight, $\quad 0.6 \pm 0.9 \mathrm{~kg} / \mathrm{m}^{2}$; normal, $0.5 \pm 0.4 \mathrm{~kg} / \mathrm{m}^{2}$ ); while the patients in the overweight group showed moderate decreases in BMI $\left(-0.4 \pm 0.6 \mathrm{~kg} / \mathrm{m}^{2}\right)$. In the placebotafamidis treatment sequence group at month 
(a)

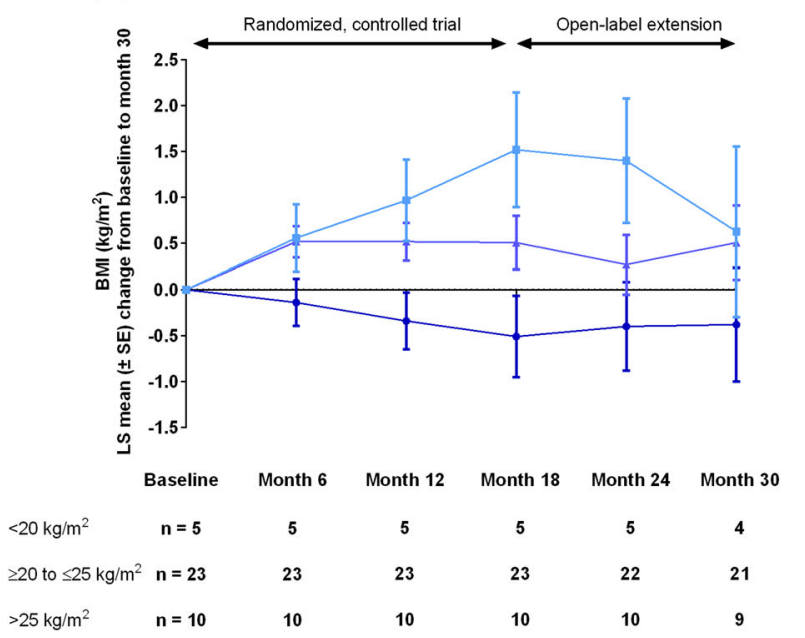

- Tafamidis/tafamidis $\left(B M I<20 \mathrm{~kg} / \mathrm{m}^{2}\right)$

- Tafamidis/tafamidis (BMI $\geq 20$ to $\leq \mathbf{2 5} \mathrm{kg} / \mathrm{m}^{2}$ )

$\rightarrow$ Tafamidis/tafamidis $\left(\mathrm{BMI}>\mathbf{2 5} \mathrm{kg} / \mathrm{m}^{2}\right)$

Fig. 3 BMI change from baseline to on-treatment timepoints. BMI body mass index, $L S$ least squares, $S E$ standard error, TTR-FAP transthyretin familial amyloid polyneuropathy

30, underweight patients remained at their prerandomization BMI. The patients in the normal baseline group showed a moderate increase in BMI at month $30\left(0.8 \pm 0.6 \mathrm{~kg} / \mathrm{m}^{2}\right)$, whereas the patients in the overweight group showed a small decrease in BMI $\left(-0.1 \pm 0.5 \mathrm{~kg} / \mathrm{m}^{2}\right)$.

\section{DISCUSSION}

This was a post hoc analysis of two interventional studies involving patients with Val30Met TTR-FAP. The main finding is the improvement in, or maintenance of, nutritional status associated with tafamidis treatment in these patients. Particularly noteworthy was the reversal of decline in mBMI observed in the placebo group following the switch to tafamidis in the extension study. The Val30Met TTR-FAP patients under study had early-stage disease, with preserved nutritional status as evidenced by the participation of overweight individuals. It was therefore not expected, or desired, that BMI would steadily increase during the tafamidis treatment period. An interesting finding was that the BMI increase associated with tafamidis was largely confined to those with relatively low values in whom an improvement is desired.

The patients summarized in this analysis are only those who continued into the open-label extension (i.e., within 2 months of completing the randomized trial) and received at least one dose of tafamidis. While selection bias may have been introduced into the ITT population of the extension study due to loss of the randomization process, the authors believe that the degree of selection bias is minor as the tafamidis and placebo groups were matched regarding demographics and clinical characteristics at baseline, and most patients discontinued the randomized, controlled trial to obtain liver transplants. It should be further noted that the studies were short relative to the duration of disease. Nevertheless, our findings that tafamidis was associated with maintaining or improving mBMI over a 2.5 -year period in 
patients with Val30Met TTR-FAP, as well as exerting the most beneficial effects on BMI in underweight patients, underscore the importance of detecting and treating TTR-FAP promptly. This enables patients with early-stage disease to obtain the benefits of therapy while they still have the physiologic capacity to recover and maintain some of their nutritional health. In a single-center, non-randomized, controlled trial conducted in France of 37 consecutive patients with late-stage Val30Met TTR-FAP, tafamidis was associated with negligible efficacy on neurological function and disability [22]. It could be argued that the mBMI improvement observed is related to an increased appetite and not related to tafamidis efficacy; however, the finding of a more pronounced effect on patients presenting with low mBMIs makes such an assumption less convincing. In addition, the nonsteroidal antiinflammatory drug (NSAID) diflunisal, which also showed efficacy as a disease modifying agent in a recent controlled trial [20], only had a modest impact on mBMI. Nausea and dyspepsia are common adverse effects of NSAIDs [21], which may explain the more modest response in $\mathrm{mBMI}$ among diflunisal recipients in the trial.

In addition to the utility of mBMI as a postsurgical outcome predictor [12, 23], this simple and easy to use internal medicine tool can be a reliable measure reflecting the clinical course of TTR-FAP and treatment response. Improvements in mBMI coincide with improvements in neurologic function and quality of life [15, 24], while deteriorating mBMI is associated with disease progression [11]. In Portuguese patients with Val30Met TTRFAP, weight loss preceded neurological and gastrointestinal symptoms in a substantial proportion of the patients [7]. Although data from prospective, observational studies revealed that patients with an mBMI $<700 \mathrm{~kg} / \mathrm{m}^{2} \mathrm{~g} / \mathrm{l}$ have lower survival rates than patients with higher mBMIs after liver transplant [12, 23], there is no absolute threshold value identifying patients with a normal mBMI from those without. In a cross-sectional observational study, healthy volunteers had a mean mBMI of $1,199 \mathrm{~kg} / \mathrm{m}^{2} \mathrm{~g} / \mathrm{l}$, which was statistically significantly higher than those of Portuguese Val30Met TTR-FAP patients with stage 1 disease (independent ambulation, $n=29 ; 1,031.9 \mathrm{~kg} /$ $\mathrm{m}^{2} \mathrm{~g} / \mathrm{l}$ ), stage 2 disease (assistance required to walk, $\left.n=16 ; 886.4 \mathrm{~kg} / \mathrm{m}^{2} \mathrm{~g} / \mathrm{l}\right)$, and stage 3 disease (wheelchair bound or bedridden, $n=16 ; 759.7 \mathrm{~kg} / \mathrm{m}^{2} \mathrm{~g} / \mathrm{l}$ ) [25].

Further research is warranted to investigate the biological effects of active amyloidogenesis on gastrointestinal structure and function, as well as any beneficial effects that tafamidis has in attenuating this aspect of the disease process. mBMI may shed some light on gastrointestinal TTR amyloidosis etiology, as there is a weak but significant negative correlation between this measure and gastric emptying (Spearman rank-order coefficient, $0.218, P=0.006)$ in patients with Val30Met TTR-FAP [9]; it is reasonable to suggest that the BMI component of mBMI would be negatively impacted by the classic early-stage symptoms of gastroparesis (i.e., nausea, vomiting, and early satiety) [26]. The mechanisms by which amyloidogenesis causes gastric retention have yet to be elucidated but this problem is evident in patients with normal sympathetic and parasympathetic activity, and only weakly correlated with autonomic neuropathy [9]. Both factors of the mBMI composite endpoint (BMI and serum albumin level) are expected to be negatively impacted by the late-stage disease often associated with malabsorption. Although depletion of neuroendocrine cells along the gastrointestinal tract from the 
stomach to the colon was hypothesized to engender gastrointestinal disturbances [27-29], no improvement of gastrointestinal function was found after liver transplant [30-32], even when the endocrine cell count in the upper part of the tract normalized [30]. Attention has turned to the loss of interstitial pacemaker cells of Cajal as a potential contributing factor involved in TTR-FAP gastrointestinal complications. The numbers of these mesenchymal cells were depleted in the gastric wall of 11 deceased Japanese patients with Val30Met TTR-FAP and attendant gastrointestinal complications, compared with 10 deceased non-TTR-FAP patients [33]. Interestingly, similarities between the gastroenteropathies associated with TTR-FAP and type 2 diabetes mellitus may be relevant. Accumulation of advanced glycation end products, which bind to enteric neurons and cause decreased production of nitric oxide synthase, leading to a delayed gastric emptying in diabetics [34], has also been observed in amyloid-rich tissues of TTR-FAP patients [35]. The smooth muscle degeneration and fibrosis contributing to the gastroenteropathy of diabetes mellitus $[34,36$, 37] also requires investigation in TTR-FAP.

\section{CONCLUSION}

The delay in neurological deterioration brought about by tafamidis treatment in clinical trials of patients with early-stage Val30Met TTR-FAP was associated with changes in mBMI measurements as a result of improvements in, or maintenance of, weight and serum albumin levels. $\mathrm{mBMI}$ is an integrative physiologic indicator which is useful for monitoring disease progression and treatment response in patients with TTR-FAP.

\section{ACKNOWLEDGMENTS}

This study and Article Processing Charges were sponsored by Pfizer Inc., New York, USA. Editorial support for the development of this manuscript was provided by Malcolm Darkes of Engage Scientific Solutions, Horsham, UK, and was funded by Pfizer Inc., New York, USA.

Conflict of interest. OBS served as an advisor for Alnylam Pharmaceuticals and Pfizer Inc., as well as having served as an advisor and received support as a clinical investigator from FoldRx Pharmaceuticals, which was acquired by Pfizer Inc. in October 2010. He currently serves on the THAOS (a disease registry capturing natural history and effect of therapies on the TTR amyloidoses) scientific advisory board. IMC received honoraria from serving on the scientific advisory board of FoldRx Pharmaceuticals, and served as primary investigator and received research support from FoldRx Pharmaceuticals/Pfizer Inc. She currently serves on the THAOS scientific advisory board. B-GE has received support from Pfizer Inc. for scientific lectures. ONK, FSM, and PEH are are employees of Pfizer Inc.

Compliance with ethics. Both study protocols were approved by the local scientific ethical committees and regulatory authorities, and conducted in accordance with the ethical standards of the responsible committee on human experimentation (institutional and national) and with the Helsinki Declaration of 1975, as revised in 2000 and 2008. Informed consent was obtained from all patients for being included in the study.

Authors' contributions. All authors were responsible for the initial conception and drafting of the manuscript. FSM gathered the 
data. All authors revised the preliminary drafts of the manuscript, and read and approved the final manuscript.

Open Access. This article is distributed under the terms of the Creative Commons Attribution Noncommercial License which permits any noncommercial use, distribution, and reproduction in any medium, provided the original author(s) and the source are credited.

\section{REFERENCES}

1. Plante-Bordeneuve V, Said G. Familial amyloid polyneuropathy. Lancet Neurol. 2011;10:1086-97.

2. Anan I, El-salhy M, Ando Y, Terazaki H. Suhr OB: comparison of amyloid deposits and infiltration of enteric nervous system in the upper with those in the lower gastrointestinal tract in patients with familial amyloidotic polyneuropathy. Acta Neuropathol. 2001;102:227-32.

3. Connors LH, Lim A, Prokaeva T, Roskens VA, Costello CE. Tabulation of human transthyretin (TTR) variants, 2003. Amyloid. 2003;10:160-84.

4. Saraiva MJ. Transthyretin mutations in health and disease. Hum Mutat. 1995;5:191-6.

5. Wixner J, Mundayat R, Karayal ON, Anan I, Karling P, Suhr OB. THAOS: gastrointestinal manifestations of transthyretin amyloidosis-common complications of a rare disease. Orphanet J Rare Dis. 2014;9:61.

6. Hund E, Linke RP, Willig F, Grau A. Transthyretinassociated neuropathic amyloidosis. Pathogenesis and treatment. Neurology. 2001;56:431-5.

7. Coutinho P, Martins da Silva A, Lopes Lima J, Resende Barbosa A. Forty years of experience with type I amyloid neuropathy: review of 483 cases. In: Glenner GG, Pinho e Costa P, de Falcao Freitas A, editors. Amyloid and amyloidosis. Amsterdam: Excerpta Medica; 1980. p. 88-98.

8. Guirl MJ, Hogenauer C, Santa Ana CA, Porter JL, Little KH, Stone MJ, Fordtran JS. Rapid intestinal transit as a primary cause of severe chronic diarrhea in patients with amyloidosis. Am J Gastroenterol. 2003;98:2219-25.

9. Wixner J, Karling P, Rydh A, Hornsten R, Wiklund U, Anan I, Suhr OB. Gastric emptying in hereditary transthyretin amyloidosis: the impact of autonomic neuropathy. Neurogastroenterol Motil. 2012;24:e1111-568.

10. Steen L, Ek B. Familial amyloidosis with polyneuropathy. A long-term follow-up of 21 patients with special reference to gastrointestinal symptoms. Acta Med Scand. 1983;214:387-97.

11. Suhr O, Danielsson A, Holmgren G, Steen L. Malnutrition and gastrointestinal dysfunction as prognostic factors for survival in familial amyloidotic polyneuropathy. J Intern Med. 1994;235:479-85.

12. Franz C, Hoffmann K, Hinz U, Singer R, Hund E, Gotthardt DN, Ganten T, Kristen AV, Hegenbart U, Schonland S, Hinderhofer K, Buchler MW, Schemmer P. Modified body mass index and time interval between diagnosis and operation affect survival after liver transplantation for hereditary amyloidosis: a single-center analysis. Clin Transplant. 2013;27(Suppl 25):40-8.

13. Bulawa CE, Connelly S, Devit M, Wang L, Weigel C, Fleming JA, Packman J, Powers ET, Wiseman RL, Foss TR, Wilson IA, Kelly JW, Labaudiniere R. Tafamidis, a potent and selective transthyretin kinetic stabilizer that inhibits the amyloid cascade. Proc Natl Acad Sci USA. 2012;109:9629-34.

14. Vyndaqel $20 \mathrm{mg}$ soft capsules: Summary of product characteristics. European public assessment report. Pfizer Specialty UK Limited. Available online at URL: http://www.ema.europa.eu/docs/en_GB/ document_library/EPAR_-_Product_Information/ human/002294/WC500117862.pdf [Accessed 13th February 2013].

15. Coelho T, Maia LF, Martins da Silva A, Waddington Cruz M, Plante-Bordeneuve V, Lozeron P, Suhr OB, Campistol JM, Conceicao IM, Schmidt HH, Trigo P, Kelly JW, Labaudiniere R, Chan J, Packman J, Wilson A, Grogan DR. Tafamidis for transthyretin familial amyloid polyneuropathy: a randomized, controlled trial. Neurology. 2012;79:785-92.

16. Coelho T, Maia LF, da Silva AM, Cruz MW, PlanteBordeneuve V, Suhr OB, Conceicao I, Schmidt HH, Trigo P, Kelly JW, Labaudiniere R, Chan J, Packman J, Grogan DR. Long-term effects of tafamidis for the treatment of transthyretin familial amyloid polyneuropathy. J Neurol. 2013;260:2802-14.

17. Revising the Declaration of Helsinki: Bulletin of medical ethics 2000:9-11.

18. Kim DH, Zeldenrust SR, Low PA, Dyck PJ. Quantitative sensation and autonomic test abnormalities in transthyretin amyloidosis polyneuropathy. Muscle Nerve. 2009;40:363-70. 
19. Vinik EJ, Vinik AI, Paulson JF, Merkies IS, Packman J, Grogan DR, Coelho T. Norfolk QOL-DN: validation of a patient reported outcome measure in transthyretin familial amyloid polyneuropathy. J Peripher Nerv Syst. 2014;19:104-14.

20. Coelho T, Merkies I, Vinik A, et al. Relationship between objective measures of neuropathy and quality of life in stages of severity of transthyretin familial amyloid polyneuropathy. Amyloid. 2010;17(suppl 1):138.

21. Koike H, Misu K, Ikeda S, Ando Y, Nakazato M, Ando E, Yamamoto M, Hattori N, Sobue G. Type I (transthyretin Met30) familial amyloid polyneuropathy in Japan: early- vs late-onset form. Arch Neurol. 2002;59:1771-6.

22. Lozeron $\mathrm{P}$, Theaudin $\mathrm{M}$, Mincheva Z, Ducot B, Lacroix C, Adams D. Effect on disability and safety of tafamidis in late onset of Met30 transthyretin familial amyloid polyneuropathy. Eur J Neurol 2013;20:1539-45.

23. Suhr OB, Ericzon BG, Friman S. Long-term followup of survival of liver transplant recipients with familial amyloid polyneuropathy (Portuguese type). Liver Transpl. 2002;8:787-94.

24. Said G, Grippon S, Kirkpatrick P. Tafamidis. Nat Rev Drug Discov. 2012;11:185-6.

25. Vinik EJ, Vinik AI, Paulson JF, Merkies IS, Packman J, Grogan DR, Coelho T. Norfolk QOL-DN: validation of a patient reported outcome measure in transthyretin familial amyloid polyneuropathy. J Peripher Nerv Syst 2014;19:104-14.

26. Suhr O, Danielsson A, Steen L. Bile acid malabsorption caused by gastrointestinal motility dysfunction? An investigation of gastrointestinal disturbances in familial amyloidosis with polyneuropathy. Scand J Gastroenterol. 1992;27:201-7.

27. Anan I, El-Salhy M, Ando Y, Nyhlin N, Terazaki H, Sakashita N, Suhr O. Colonic endocrine cells in patients with familial amyloidotic polyneuropathy. J Intern Med. 1999;245:469-73.

28. El-Salhy M, Suhr O, Stenling R, Wilander E, Grimelius L. Impact of familial amyloid associated polyneuropathy on duodenal endocrine cells. Gut. 1994;35:1413-8.

29. Nyhlin N, Anan I, El-Salhy M, Ando Y, Suhr OB. Endocrine cells in the upper gastrointestinal tract in relation to gastrointestinal dysfunction in patients with familial amyloidotic polyneuropathy. Amyloid. 1999;6:192-8.

30. Anan I, El-Salhy M, Nyhlin N, Suhr OB. Liver transplantation restores endocrine cells in patients with familial amyloidotic polyneuropathy. Transplantation. 2000;70:794-9.

31. Lang K, Wikstrom L, Danielsson A, Tashima K, Suhr OB. Outcome of gastrointestinal complications after liver transplantation for familial amyloidotic polyneuropathy. Scand J Gastroenterol. 2000;35:985-9.

32. Suhr OB, Anan I, Ahlstrom KR, Rydh A. Gastric emptying before and after liver transplantation for familial amyloidotic polyneuropathy, Portuguese type (Val30Met). Amyloid. 2003;10:121-6.

33. Wixner J, Obayashi K, Ando Y, Karling P, Anan I. Loss of gastric interstitial cells of Cajal in patients with hereditary transthyretin amyloidosis. Amyloid. 2013;20:99-106.

34. Kashyap P, Farrugia G. Diabetic gastroparesis: what we have learned and had to unlearn in the past 5 years. Gut. 2010;59:1716-26.

35. Matsunaga N, Anan I, Forsgren $S$, Nagai $R$, Rosenberg P, Horiuchi S, Ando Y, Suhr OB. Advanced glycation end products (AGE) and the receptor for $\mathrm{AGE}$ are present in gastrointestinal tract of familial amyloidotic polyneuropathy patients but do not induce NF-kappaB activation. Acta Neuropathol. 2002;104:441-7.

36. Ejskjaer NT, Bradley JL, Buxton-Thomas MS, Edmonds ME, Howard ER, Purewal T, Thomas PK, Watkins PJ. Novel surgical treatment and gastric pathology in diabetic gastroparesis. Diabet Med. 1999;16:488-95.

37. Ordog T. Interstitial cells of Cajal in diabetic gastroenteropathy. Neurogastroenterol Motil. 2008;20:8-18. 